Research Article

\title{
DOCUMENTATION OF INDIGENOUS TECHNICAL KNOWLEDGE AND THEIR APPLICATION IN PEST MANAGEMENT IN WESTERN MID HILL OF NEPAL
}

\author{
K. Naharki* and M. Jaishi \\ Institute of Agriculture and Animal Science, Lamjung Campus, Tribhuvan University, Nepal
}

\begin{abstract}
Indigenous technical knowledge (ITK) are based on the experiences of the local people being passed on from one generation to next and has been used for management of pest since ancient times. A study was conducted to collect and document the ITK and their application in pest management from indigenous communities in western mid hill of Nepal. A total sample size of seventy-five respondents from the indigenous communities of Magar, Gurung, and Newar in Tanahun, Lamjung and Kaski districts of Nepal were interviewed with a semi structured questionnaire. The study revealed that subsistence farmers and semi commercial farmers usually made the most use of ITK while commercial farmers rarely used such indigenous knowledge. Use of ITK was highest $(85 \%)$ by the subsistence farmers, followed by semi-commercial farmers $(60 \%)$, and lowest $(10 \%)$ by commercial farmers in pest management. The transfer of ITK was mostly found to be through past generations. The indigenous technological knowledge being applied in pest management should be documented, promoted, and encouraged in combination with scientific knowledge among the farming communities.
\end{abstract}

Keywords: Documentation, ITK, Pest Management

\section{INTRODUCTION}

Indigenous technical knowledge (ITK) is the fundamental part of the culture and history of a local community (Borthakur and Singh, 2012). It is the knowledge of the indigenous people residing in different geographical regions of the world with their own techniques, practices, skill and culture (Bruchac, 2014). ITK are distinctive, traditional and local knowledge prevailing within and developed around specific communities indigenous to a particular area (Ghosh, 2011). We need to learn from local communities to augment the development process (Pongel, 2011). ITK are those skills and practices which are developed over a period of time through accumulation of experience and understanding by the native communities and are

* Corresponding author: kushalnaharki@gmail.com 
inherited from generation to generation (Devi et al., 2014). ITK are the storage house of knowledge, skills and techniques for management of farming system. They are transferred through sharing of cultural and traditional information (Singh, 2007).

Nepal is inhabited by a multiethnic, multi-cultural and multi-lingual communities endowed with rich ITK for agricultural practices (MoFSC, 2014). Fifty-Nine indigenous nationalities have been recognized in Nepal referred as 'Adivasi Janajati' which consist of 35.8 percent of the total population of Nepal (NEFIN, 2018). Gurungs, known as Tати are the major indigenous inhabitant of western mid hill and Magar are the indigenous inhabitant in the western and mid-western Nepal (Bhattachan, 2012). All of these indigenous communities have some kind of traditional knowledge associated with their life from time immemorial. But none of the national policies in Nepal has emphasized the documentation of these ITK and related issues (Sharma et al., 2009).

ITK is sustainable as it has evolved after many years of observation and experience. They are important tools for advancement as ITK are farmer friendly, innovation of site-specific crop management practices, conservation of natural resource base, resilient and adaptation to changing climate and food security (UNFCCC, 2013).Traditional farm practices should be promoted and encouraged among the farming communities as an effort not only to tap the local knowledge but also to make use of locally available resources in crop management (Narayanasamy, 2001).Documentations will help in developing the contents of indigenous technological knowledge which will be disseminated to the entire community for its future implication (Pradhan et al., 2017).

Plant protection has become a serious matter due to changes in climate. The ecology and biology of different insect pests are also changing which makes pest control mechanisms more difficult and complex (Singh et al., 2019). Chemical pesticides are used in agricultural field indiscriminately which has resulted in to resistance development in pests along with environmental degradation (Gill and Garg, 2014). Pest management approaches are different among traditional farmers practicing traditional farming systems in different regions of the country (Chhetry and Belbahri, 2009). Indigenous pest management practices generally involve use of locally available resources for the successful cultivation of crop plants and hence are ecofriendly and sustainable. ITK being applied in pest management have inherent characteristics of cultural and environmental compatibility as well as sustainability with cost-effectiveness (Pradhan et al., 2017).

Transformation of socio-economic conditions of rural people and the resulting changes in agricultural processes have resulted in decreased use of associated traditional knowledge with shift to modern practices (Uprety, 2012).Lack of documentation of ITK, low awareness about its scientific rationality and poor research advances are the major constraints of wider ITK applicability (Devi et al., 2014). The recognition of the creativity of the traditional communities is essential for 
the conservation of biodiversity as well as conservation of intellectual diversity by the farmers of the community to continue to the further generations (Jena, 2007). The present study attempts to document the ITK and their application related to pest management as used by farmers of indigenous communities in western mid western hill of Nepal.

\section{MATERIALS AND METHOD}

\section{Study area and design}

A study was conducted to collect and document ITK and their application on pest management from indigenous farmers and local information resources. The survey was conducted in the indigenous community's inhabitant in Tanahun, Lamjung and Kaski district of Nepal (Fig. 1). A total sample size of seventy-five respondent was interviewed with a semi structured and open-ended questionnaire between November 2019 and January 2020.The qualitative data were recorded from the survey. Twentyfive respondents from each communities of Magar, Gurung and Newar were selected on the basis of purposive random sampling in indigenous communities.

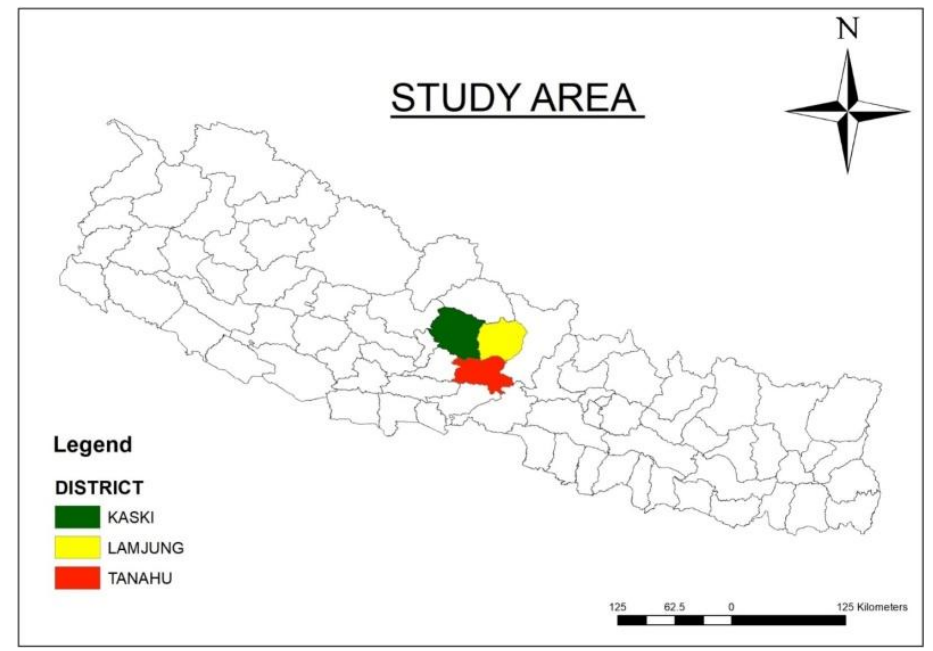

Figure 1. Map of Nepal showing study area

\section{Documentation and statistical analysis}

Focus group discussion (FGD), transect walks, observation and key informant interview were qualitative research methods used for the validation and documentations of ITK. Secondary data were collected reviewing different scholarly publications, journals, books and local information. The analysis of data was performed using SPSS (Version-25.0) and MS Excel 2016.

Rationality refers to the degree of perceived effectiveness of ITK or explanation and support of ITK with scientific rationale (Husain and Sundaramari, 2011). Rationality 
scale (Hiranand, 1979) was used to judge the rationality of the indigenous practices. FGDs were conducted in each of three indigenous communities with participation respondents and key informants to determine the rationality of the ITK. The ITK validated for the rationality by discussions based on perceived effectiveness were documented.

\section{Sources of ITK}

\section{RESULTS AND DISCUSSION}

From the survey, it was found that ITK are transferred from past generations such as elder persons, parents and grandparents. About $82 \%$ of the respondents received the knowledge on ITK from their past generations where as $6 \%$ of the respondents received the knowledge through studies, journals, newspapers and articles (Fig. 2). About $12 \%$ of the respondents received the knowledge from other sources such as imitation of their neighbors, community leaders, extension agenesis and seeing it being performed by other people.

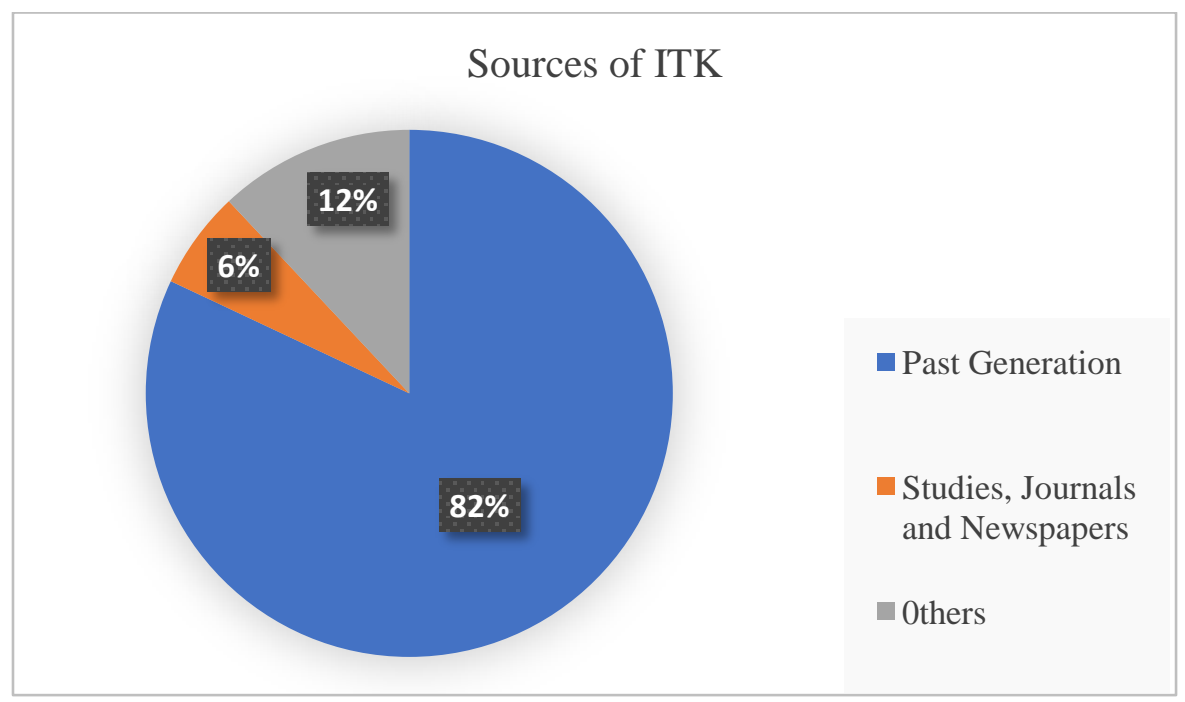

Figure 2. Sources of ITK

There are many sources of ITK hidden in our village and societies (Satapathy et al., 2002). ITK is irregularly dispersed in communities and the valuable sources of ITK are farmers, community members and importantly elders. They are perceived by next generation through word of mouth, sights and writings (Arora et al., 2016).

\section{ITK used by the indigenous communities of western mid hill of Nepal}

Technical methods used in indigenous communities of western mid hill of Nepal in pest management are: 


\section{Drying of harvested products}

Originally the traditional practice was that the maize cobs were kept dried by keeping them on the top floor where kitchen heat would facilitate drying of the seeds. They are also hanged outside forming a cluster called 'Suli' and 'Thangra'. Drying reduces the crop moisture content and susceptibility of the storage insect pest in grains (Asemu et al., 2020).

\section{Dusting of ash}

Ash is dusted to control aphids. It is also used to control ants in potato field. Application of ash repels insects and discourages surface feeding insects (Chandola et al., 2011).

\section{Ethnobotanical use of locally available plants}

Use of herbs like Neem, Bojho, Marigold, Titepatiare used for the management of various pests depending on their local availability.

\section{Field burning}

This method is performed to kill any insects or eggs of insects that may be present in the field. When population of insects increases beyond limit and becomes out of control, entire farm infested with insect pest are burnt to prevent the pest from spreading elsewhere. Field burning improves yield and reduce the requirement of pesticides and fertilizers. Slash and burn is still being practiced in different parts of Nepal including western mid hills of Nepal (Kafle, 2011).

\section{Foliar spray of cow urine}

Cow urine is sprayed over the plant as it acts as pest repellant. Cow urine, ash and soil mixture is useful for the treatment of cabbage plants. Cow urine is also used for the preparation locally made compost called 'Jhol Mol'. Nitrogen present in the urine also favors the development of the crops. Cow urine is used in rice field with damage of snails and slugs as they have molluscicidal effect (Deshmukh, 2015).

\section{Irrigation}

Application of fresh irrigation water helps to control pest during outbreak. Drying and wetting of rice field for few days is also one of the indigenous practices followed by the farmers especially against case worm and leaf folder in rice. The grounded pulp of the 'Khirro' leaf is used in irrigation channel to control Rice stem borer.

\section{Planting attractant/repellent crops on border of field}

Traps crops are used in the borders as attractants and repellents to protect the main crop field from insect pests. Mustard crops are planted on border of wheat field and coriander on border of Cole to attract the crop away from the major field. Marigold plants are also used as trap crop in many vegetable and cereal crops. 


\section{Ploughing}

Ploughing with traditional plough called 'Halo' is performed before plantation to remove the weeds and killing of eggs of insect.

\section{Preparation of indigenous pesticide}

Indigenous pesticide is prepared using cow urine and jaggery. The toxicity of the mixture kills the insects and pests that come in contact with it. Botanicals, cow urine and cow dung are mixed in various ratios for the preparation of indigenous pesticides.

\section{Storage in bamboo container}

Bamboo containers made up of bamboo called 'Bhakari' are used to keep away the storage pests.

\section{Use of cow dung}

Cow dung is also used as seed protector. Seed is covered in cow dung before they are planted. It helps to protect seeds from pests. It is reported that cow dung extract @ $2 \%$ concentration is effective against ear head bug, BPH, leaf folder, stem borer, caterpillars and other chewers in rice (Narayanasamy, 2001).

\section{Use of scare crow to scare birds and animals}

Scare crow are used to scare the birds and animals that destroy the crops. These are specially kept in cereal crop field like rice, wheat and maize or vegetable and fruit fields.

\section{Using stick}

Rice moths are found to create clusters on paddy plants. They are removed with sticks and the moths submerged on the water in the field to kill them.

\section{ITK in weed management}

Weeds are the major host of pests in agriculture. Indigenous communities perform management of weed for the control of pest in field. During intercultural operations, hand or manual weeding is carried out and burning is still prevalent. Flooding is carried out in rice field to suppress the growth weeds. Slicing of bunds and terrace raisers is carried out before sowing in the field. On rainfed field, flooding through irrigation is carried out for effective weed control. Wooden rake called 'Dante' is used to collect the weed in the field during ploughing. Mixed cropping and inter cropping to utilize the inter row space is also practiced which helps to suppress weeds and increase weed control efficiency (Ghuman et al., 2008). Retention of weeds in field and the crop residues before sowing also occurs which helps in increase in nutrient content of soil and enhancement in soil quality (Duke et al., 2002) 


\section{Application of ITK in pest management}

Among the respondents, there were 10 commercial farmers, 32 semi commercial farmers and 33 subsistence farmers. From the survey, the result revealed subsistence farmers and semi commercial farmers usually make the most use of the ITK and is seldom used by the commercial farmers. Use of ITK was found to be $85 \%$ in subsistence farmers, $60 \%$ in semi commercial farmers and $10 \%$ among commercial farmers (Fig. 3).

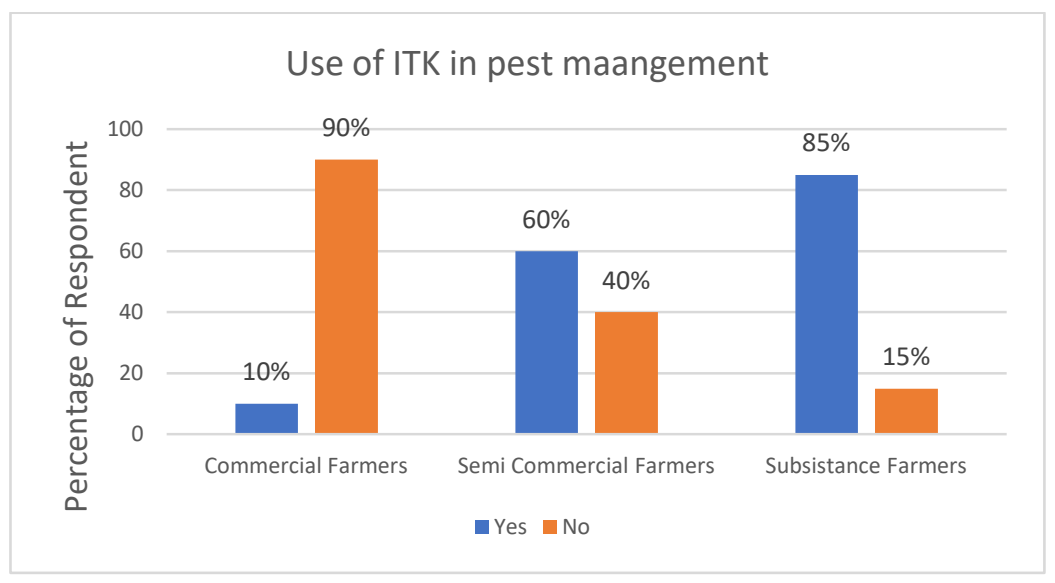

Figure 3. Use of ITK by different types of farmers

The communities have used the indigenous knowledge system to conserve and utilize the biological diversity of their surroundings (Jena, 2007). ITK are cheap, local and generally perceived through parents which makes it easier to adopt and use for the subsistence and semi commercial farmers (Nkunika,2002) whereas commercial farmers prefer use of costly pesticides which give immediate results (Palikhe, 2002)

\section{Application of botanicals for pest management}

Farmers use plant materials for protection of plants from pests and for improving the nutritional status of the soil. Among the plants available locally, titepati, banmara, neem and asuro were found to play an important role in pest management in indigenous communities.

Botanical pesticides can be a good alternative to minimize the use of synthetic pesticides as they possess the properties of pest repellence, toxicity, anti-feedance, and insect growth regulatory activities against pests of agricultural importance (Matharu and Chahil, 2013). Moreover, they are safe and easier to use, locally available and cost effective. Plants like Azardirachta indica, Vitex nedundo, Ricinus communis, Gliricidia sepium, Euphorbia milli, Euphorbia tirucalli are proved to be the best natural pest control plants (Deshmukh, 2015). Many botanicals are being used as ITK for pest management in different crops and most of them have medicinal properties which can keep the environment safe (Joshi and Joshi, 2002). 
Table 1. Locally available botanicals used for insect control in the study area

\begin{tabular}{|l|l|l|l|}
\hline \multicolumn{1}{|c|}{$\begin{array}{c}\text { Local } \\
\text { Name }\end{array}$} & \multicolumn{1}{|c|}{$\begin{array}{c}\text { Common } \\
\text { Name }\end{array}$} & \multicolumn{1}{|c|}{ Scientific Name } & \multicolumn{1}{c|}{ Insects Controlled } \\
\hline Asuro & Malabar nut & Adhatoda visica & $\begin{array}{l}\text { Grasshopper, Scale Insects, Stored pest, Rice } \\
\text { pest }\end{array}$ \\
\hline Bakaino & China berry & Melia azedarach & $\begin{array}{l}\text { Army worm, Mustard saw-fly, Tobacco } \\
\text { caterpillar }\end{array}$ \\
\hline Banmara & Wild Sage & Lantana camara & Corn weevil, Beetle \\
\hline Bojho & Sweet Flag & Acorus calamus & Ants, Maize Weevil \\
\hline Gande & Billy goat & Aegeratum conizoides & Diamond back moth, Stored Grain Pest \\
\hline Khirro & Milk Tree & Sapium insigne & Stem borer \\
\hline Nim & Neem & Azadirachta indica & $\begin{array}{l}\text { Rice pests, Diamond back moth, Stored } \\
\text { grain pests including weevil and grain moth. }\end{array}$ \\
\hline Sayapatri & Marigold & Tagetes erecta & $\begin{array}{l}\text { Rice green leafhopper, Brown planthopper, } \\
\text { Diamond back moth, aphid }\end{array}$ \\
\hline Titepati & Mugwort & Artemisia vulgaris & Corn borer, Leaf mines and galls control \\
\hline Tulsi & Sweet Basil & Ocimum basilicum & Rice Pest, Beetles, Fruit flies \\
\hline
\end{tabular}

\section{Constraints in ITK Documentation}

The knowledge on agricultural systems and pest management is accumulated, improved and preserved through personal experiences by farmers themselves and is documented very little in particular. Although, several technical methods are used in pest management since ancient time, they lack scientific validation and documentation in detail. There are no written documents on ITK available with the local farmers. Agricultural agencies, extension workers, research institutions and government bodies have felt short to explore this topic. Lack of research activities related to ITK in pest management practices and their protection for future application acts as major constraints in documentation. ITK are in the threat of extinction due to lack of systematic documentation, lacking incorporation in agricultural research and development by researcher and extension worker (UNDRIP, 2007).

\section{CONCLUSION}

ITK are valuable assets to indigenous communities. They are used combining traditional skills, culture, knowledge and tools of the native communities. The documented ITK showed importance and effectiveness in controlling insects and pest management. ITK-based practices are used by the majority of the subsistence and semi commercial farming community without the knowledge of its scientific rationality. Effective actions should be taken to preserve and promote ITK with 
blending of indigenous and scientific knowledge. There is necessity to combine ITK with the scientific cognizance strategy with its proper documentation and apply them in pest management with rationality for their use of ITK in future.

\section{ACKNOWLEDGEMENT}

Sincere gratitude is expressed to Prof. Megha N Parajulee and Mr. Kapil Kafle for devoting their valuable time during the research work and preparation of the article. Sincere thanks to Sudip Regmi, Sabina Regmi,Shikshya Parajuli and Bhanubhakta Adhikari for their valuable suggestion and guidance throughout the work.

\section{REFERENCES}

Asemu, A.M., Habtu,G.B., Subramanyam,B., Delele, M.A. Kalsa, K.K. and Alavi S. (2020). Effects of grain drying methods on postharvest insect infestation and physicochemical characteristics of maize grain. Journal of Food Process Engineering, doi: $10.1111 /$ jfse./13423.

Arora, S., Sharma, J.P., Chakravorty, S., Sharma N. and Joshi P. (2016). Indigenous Technologiesin Plant Protection. ICAR - National Research Centre for Integrated Pest Management, New Delhi, India. Pp.15-20.

Bhattachan, K.B. (2012). Country Technical Notes on Indigenous Peoples' Issues Federal Democratic Republic of Nepal. International Fund for Agricultural Development (IFAD). Pp. 2-5.

Borthakur, A. and Singh P. (2012). Indigenous Technical Knowledge (ITK) and their Role in Sustainable Grassroots Innovations: An Illustration in Indian Context. Proceedings of International Conference on Innovation and Research in Technology for Sustainable Development (ICIRT) held at India. Pp. 38-42.

Bruchac, M. (2014). Indigenous Knowledge and Traditional Knowledge In Encyclopedia of Global Archaeology. Newyork: Springer Science and Business Media, NY. Pp. 39-82.

Chandola, M., Rathore, S. and Kumar B. (2011). Indigenous pest management practices prevalent among hill farmers of Uttarakhand. Indian Journal of Traditional Knowledge, 10(2): 311-315.

Chhetry, G. and Belbahri, L. (2009). Indigenous pest and disease management practices in traditional farming systems in north east India. A review. Journal of Plant Breeding and Crop Science, 1(3): 28-38.

Deshmukh, P.S. (2015). A Case Study : Traditional Methods of Pest Control in Some Villages of KolhapurDistrict. Online International Interdisciplinary Research Journal, 5(3):87-92

Devi, R., Pandit, A. and Kashyap, D. (2014). Assessment of applicability of Indigenous Technical Knowledge (ITK) in aquaculture as perceived by fish farmers in Assam. Indian Journal of fisheries, 61(3):104-110

Duke, S.O., Dayan, F.E., Rimando, A.M., Schrader, K., Aliotta, G., Oliva A. and Romagni, J.G. (2002). Chemicals from nature for weed management.Weed Science, 50(2): 138-151. 
Ghosh, P. (2011). Indigenous Traditional Knowledge. Orissa Review.http://orissa.gov.in/emagazine/Orissareview/2011/Jan/engpdf/66-71.pdf. Accessed 11 ${ }^{\text {th }}$ March 2020.

Ghuman, R.S., Brar, L.S. and Walia, U.S. (2008). Role of variety and plant geometry on weed management in transplanted rice (Oryza sativa L.). Indian Journal of Weed Science, 40: 137-141.

Gill, H.K. and Garg, H. (2014). Pesticides: Environmental Impacts and Management Strategies.Pesticides: Environmental Impacts and Management Strategies, Pesticides Toxic Aspects, Marcelo L. Larramendy and Sonia Soloneski, IntechOpen,

Haverkort, B. (1995). Agricultural Development with a Focus on Local Resources: ILEIA'S view on Indigenous Knowledge, In The Cultural Dimensions of Development: Indigenous Knowledge Systems. London: Intermediate Technology Publications Ltd.

Hiranand. (1979). Technocultural profile of a dryland village and dry farming technology An international study, Ph .D. Thesis, Dept. of Extension, HAU, Hisar. Pp. 135

Husain, S. and Sundaramari, A. M. (2011). Scientific rationality and perceived effectiveness of indigenous technical knowledge on coconut (Cocosnucifera L.) cultivation in Kerala, Journal of Tropical Agriculture, 49 : 78-87.

Jena, M. (2007). Community Health Knowledge Register. The Tradition, 5: 6-10.

Joshi, A. R. and Joshi, K. (2002). Indigenous knowledge and uses of medicinal plants by local communities of the Kali Gandaki Watershed Area, Nepal. Journal of Ethnopharmacology, 73(1): 175-183.

Kafle, G. (2011).An overview of shifting cultivation with reference to Nepal. International Journal of Biodiversity and Environmental Science,3(5):147-154.

Matharu, K.S. and Chahil, G.S. (2013). Role of Neem based pesticides in organic agriculture. Popular Kheti, 1(4): 178-179.

MoFSC. (2014). NEPAL National Biodiversity Strategy and Action Plan.Goverment of Nepal. Pp. 1-5.

Narayanasamy, P. (2001). Traditional Pest Control: A retrospection. Indian Journal of Traditional Knowledge, 1(1): 40-50.

NEFIN. (2018). Alternative Report of the Indigenous Peoples of Nepal. Geneva 10,: Office of the United Nations High Commissioner for Human Rights (OHCHR).

Nkunika, P.O.Y. (2002). Smallholder Farmers' Integration of Indigenous Technical Knowledge (ITK) in Maize IPM: A Case Study in Zambia. International Journal of Tropical Insect Sciences, 22: 235-240.

Palikhe, B.R. (2002). Challenges and options of pesticide use: In the context of Nepal.Landschaftsökologie und Umweltforschung, 38: 130-141.

Pongel, A. (2011). Integrating Indigenous Knowledge for Food Security: Perspectives from the Millennium Village Project at in Nyanza Province in Kenya,. International Conference on Enhancing Food Security in the Eastern and Horn of Africa regions. Kampala, Uganda.

Pradhan, K., Radhan, K., Yolmo, Z., Saha A. and Prasad, C. (2017). Idenitification and documentation of indigenous technological knowledges regarding pest control methods in agriuclture. International Journal of Agriculture Sciences, 9(38): 4580-4584. 
Satapathy, C., Veeraswami S. and Satapathy B. (2002). Indigenous Technical Knowledge; method of Documentation and Rationalization, Souvenir on International Seminar Traditional Knowledge Health and Environment. Pp. 12-15

Sharma, S., Bajracharya R. and Sitaula B. (2009). Indigenous Technology Knowledge ( ITK ) in Watershed Management - A Review. Indian journal of traditional knowledge, $8(4): 1-14$.

Singh, B. (2007). Protection of Indigenous Knowledge and Intellectual Property Right (IPR). The Tradition, 5: 18-21.

Singh R., Singh H. and Raghubanshi A. S. (2019). Challenges and opportunities for agricultural sustainability in changing climate scenarios: a perspective on Indian agriculture. Tropical Ecology, 60: 167-185.

UNDRIP. (2007). United Nations Declaration on the Rights of Indigenous Peoples. United Nations.Pp. 2-4.

UNFCCC. (2013). Best practices and available tools for the use of indigenousand traditional knowledge and practices for adaptation, andthe application of gender-sensitive approaches and tools forunderstanding and assessing impacts, vulnerability andadaptation to climate change. United Nations Framework Convention on Climate Change .

Uprety, Y. (2012). Diversity of use and local knowledge of wild edible plant resources in Nepal. Journal of Ethnobiology and Ethnomedicine, 8(16):16. 